\title{
Abordagem metodológica do trabalho de campo como prática pedagógica em Geografia
}

\begin{abstract}
RESUMO: A presente pesquisa tem por objetivo uma abordagem metodológica sobre 0 trabalho de campo, tratando da prática pedagógica, dentro do planejamento do ensino e pelo contato com a realidade para a formação do profissional/professor de Geografia. Os procedimentos metodológicos seguiram uma seqüência de encaminhamentos assim constituída: pesquisa bibliográfica e análise dos dados. Os resultados mostraram que 0 trabalho de campo é importante instrumento na formação de professores/pesquisadores e acadêmicos, como um meio para o desenvolvimento da percepção sobre o território, num contexto menos formal que a sala de aula. Nas conclusões foi enfatizada a importância do trabalho de campo como recurso didático, pois oferece potencialidades formativas que devem ser levadas em consideração no processo ensino-aprendizagem e como prática pedagógica acessível e eficaz.
\end{abstract}

\section{Agostinho Paula Brito Cavalcanti*}

*Professor Associado do Departamento de Geografia da Universidade Federal do Piauí.

Palavras-chave: Geografia; Educação; Metodologia; Pesquisa.

Key-words: Geography; Education; Research.

ABSTRACT: The objective of this research is a methodological approach in fieldwork, dealt as a pedagogic practice, inserted into the teaching planning and by reality contact to the formation of the geography professional/teacher. The methodological process followed this sequence: bibliographic research and data analysis. The result has showed that the fieldwork is an important instrument in the formation of teachers, researchers and academic staff as a way to the development of territory perception in an environment less formal than of classroom. As results, it was shown the importance of fieldwork, as a didactic resource because it offers potentialities in the formation that one must take into consideration in the teachinglearning process and as a pedagogical practice accessible and efficient. 


\section{Introdução}

A Geografia é entendida como a ciência que se preocupa com a organização do espaço, através da análise da paisagem representando a interação da dinâmica social com os fatores naturais (dinâmica sócio-espacial), num determinado espaço da superfície terrestre.

As diferentes sociedades humanas e culturas em suas relações sociais de produção transformam ou modificam os quadros naturais, dando origem a organizações espaciais diferenciadas, alvo ou objeto de estudo da ciência geográfica.

Ao longo dos tempos ocorreram mudanças profundas na sociedade, na política, na economia e nas ciências de modo geral, afetando todo o conhecimento científico. Novas teorias e novas maneiras de entender e compreender o mundo, aliadas ao emprego maciço da tecnologia, pelo avanço dos meios de comunicações e o advento dos computadores, provocaram mudanças irreversíveis.

A ciência geográfica também foi afetada por essas mudanças, havendo uma verdadeira revolução no seu modo de pensar, aparecendo novas correntes de pensamento, preconizando a necessidade dos geógrafos se envolverem mais diretamente com os aspectos filosóficos, epistemológicos, teóricos, metodológicos e críticos, bem como deveriam se esforçar para desenvolver leis e teorias explicativas, para que a Geografia pudesse ser reconhecida como uma verdadeira ciência (cientificismo).

Tendo uma nova concepção da realidade observada, alguns geógrafos passaram a acreditar que o espaço geográfico era "abstrato", nos mesmos moldes do espaço matemático, podendo ser então estudado por meio de um conjunto de variáveis e seus atributos.

Os elementos do espaço geográfico passaram a ser medidos, calculados e quantificados, através de fontes de dados tais como dados censitários variados; mapas temáticos, cartas topográficas; fotografias aéreas; imagens de satélite, bem como através de técnicas de Sensoriamento Remoto, Geoprocessamento, modelagem de sistemas ambientais e quantificação.

Em função dessa nova maneira de entender o espaço geográfico e de levantar os dados e informações, os geógrafos, em sua maioria, passaram a desprezar o trabalho de campo na sua forma tradicional, pois para eles não havia mais a necessidade de se deslocar para o campo para observar as paisagens.

Passada esta fase, muitos geógrafos perceberam que houve um exagero no emprego desses materiais, métodos e técnicas, havendo a necessidade de repensar e valorizar novamente o trabalho de campo em sua forma tradicional. Este fato pode ser comprovado pelo aumento do número de publicações relativas a essa temática, que tem aparecido nos últimos anos.

Para estudar as paisagens visando compreender e explicar as diferentes organizações espaciais, os geógrafos procuraram utilizar trabalho de campo; denominação dada à atividade desenvolvida pelo pesquisador em Geografia que se desloca de seu gabinete de trabalho para a área ou local de seu interesse (objeto de estudo), com a finalidade de realização das observações e levantamento das informações pertinentes.

Trata-se então de um trabalho empírico, pois o pesquisador utiliza a observação e a

Geografia Ensino \& Pesquisa, v. 15, n.2, p. 165 176, maio.lago. 2011

Abordagem metodológica do trabalho de campo como prática pedagógica em Geografia verdadeiro e objetivo, através do contato direto com a realidade observada.

É através dessa prática, de significativa utilidade para a Geografia, que se deve desenvolver e impulsionar o avanço dessa ciência nos dias atuais, devendo a pesquisa de 
campo ser incentivada e valorizada pelos pesquisadores, tendo ainda uma inestimável contribuição para a prática didática e pedagógica do ensino e da aprendizagem geográfica.

O trabalho de campo é considerado como um instrumento fundamental para a construção do conhecimento geográfico na perspectiva da consolidação do pragmatismo como condição para a compreensão teórica, tendo seu valor pedagógico através do contato com a realidade para a formação do geógrafo.

O conteúdo do presente trabalho reúne importantes considerações sobre o trabalho de campo em Geografia, oferecendo subsídios para investigação e análise.

Foi abordada a importância do trabalho de campo, considerada de significativa relevância para a construção do conhecimento geográfico, a partir da extração de informações na elaboração e execução das pesquisas.

Discorrendo sobre a execução da pesquisa através da coleta de dados, descreve ainda os principais instrumentos para sua realização.

Trata também dos métodos do trabalho de campo, sendo considerados como recurso didático-pedagógico, oferecendo subsídios na formação e no processo ensino-aprendizagem.

\section{Importância do trabalho de campo na prática pedagógica}

Em um enfoque conceitual pedagógico, o trabalho de campo, na sua forma e essência é um método relevante dentro do planejamento do ensino de Geografia ou na pesquisa de campo propriamente dita.

Ao vislumbrar a possibilidade de recriar uma abordagem que integre conceitos, métodos e técnicas, no sentido de gerar uma metodologia que seja capaz de abranger alternativas de utilização e onde se mantenham a harmonia entre 0 meio ambiente e 0 processo de desenvolvimento, Cavalcanti (2006) inclui o trabalho de campo como prática pedagógica na formação de professores e/ou pesquisadores.

O trabalho de campo é gerador de conhecimento geográfico, pois representa o lugar de onde se extraem informações para a elaboração de conhecimentos teóricos, bem como é também o local onde as teorias são testadas.

Considerado e valorizado como importante instrumento para o desenvolvimento do conhecimento geográfico, o trabalho de campo faz com que o "processo de observação" se revista de real significado para o geógrafo. É através da observação que o pesquisador investiga o mundo real, na tentativa de compreendê-lo e interpretá-lo. Müller Filho (1988) atesta este fato observando que a produção geográfica, ao interpretar as realidades espaciais sob o prisma tradicional, fundamenta-se na observação: coletam-se os dados, eles são comparados, verificase o que entre eles há de comum, e, detectado o que é comum, baseiam-se padrões, formulamse generalizações.

Segundo David (2002), os trabalhos de campo e a observação sempre tiveram destaque na Geografia e é de fundamental importância que o geógrafo desenvolva a capacidade de observação de campo. Para isto, é preciso, treinar os sentidos a fim de se poder ver em detalhes a realidade observada. Para 0 autor citado, o principal instrumento do geógrafo, ao observar as paisagens ainda é o olho clínico do geógrafo.

A observação, de acordo com Gil (1995), nada mais é do que o uso dos sentidos com vistas a adquirir conhecimentos necessários para o cotidiano, podendo, porém, ser utilizada para

Geografia Ensino \& Pesquisa, v. 15, n.2, p. 165176, maio./ago. 2011

Cavalcanti, A. P. B.

ISSN 2236- 4994 
fins científicos desde que tenha um objetivo formulado de pesquisa; seja sistematicamente planejada e submetida à verificação e controle.

O processo de observação está dentro de um contexto maior que é a denominada teoria do conhecimento, sendo a mesma considerada uma das formas de se adquirir conhecimento através da utilização dos sentidos, juntamente com as outras duas que são a razão e a intuição. É através dos sentidos que nos relacionamos com o mundo exterior, sendo a visão, um dos principais, dentro os cincos que possuímos. 0 conhecimento adquirido através dos sentidos é denominado conhecimento "empírico" e segundo Oliveira (1988) significa experiência, afirmando que a única fonte de nossos conhecimentos é a experiência recebida e experimentada pelos sentidos.

Utilizando-se da visão o homem observa o mundo exterior, com a mente livre de preconceitos, acreditando que aquilo que ele vê é a realidade. Através dessa percepção sensorial, pode conhecer a verdade dos fatos, não questionando a possibilidade dos sentidos se enganarem, distorcerem a realidade ou não aprenderem a realidade como realmente ela é, pois a subjetividade não existe para o empirista.

De acordo com Kaplan (1969), em ciência, a observação é a procura do que está encoberto, não apenas porque está encoberto, mas porque o seu desnivelamento facilitará uma intima, bem fundamentada e produtiva relação com o mundo.

A observação sempre foi considerada de importância fundamental para o geógrafo, pois é através dela que se observam as paisagens com 0 intuito de desenvolver 0 conhecimento geográfico. É necessário então, fazer uma distinção entre o que se denomina de observação ou percepções cotidianas, do dia-a-dia, passivas ou não intencionais das observações científicas.

No primeiro caso reporta-se às observações do homem comum, no seu dia-a-dia e que são meramente contemplativas, sem maiores preocupações com o que está sendo observado. É o caso do deslocamento diário da casa ao local de trabalho, onde se observa sempre o mesmo trajeto, mas não se presta atenção ao que foi observado. Sobre essa questão, Kaplan (op. cit.) afirma que a observação científica é busca deliberada, com cautela e predeterminação, em contraste com a percepção da vida cotidiana, causal e em grande porção passivas.

$\mathrm{Na}$ observação dita científica existe uma intenção no ato de observar, devendo-se saber de antemão o que se quer observar, deve-se ter um propósito em mente. $O$ ato de observar é sempre norteado por alguma idéia, algum problema, ou alguma teoria, ou seja, sobre conhecimentos e experiências anteriores. Portanto, antes de efetuar qualquer observação é necessário desenvolver os conhecimentos teóricos, pois são eles que nortearão no processo de observação.

Quando os acadêmicos de Geografia estão em pesquisa de campo é necessário que já tenham aprendido em sala de aula os fundamentos teóricos para procederem corretamente 0 ato da observação.

Em uma aula prática, ao observarem uma planície fluvial, é preciso que já tenham em mente a fundamentação básica necessária para distinguirem os tipos de modelado terrestre. A esse respeito, Viadana (2005) acrescenta que a área visitada, com observações de passagem pelos trajetos estabelecidos e nos pontos de parada para melhor detalhamento dos fatos de interesse imediato, a concepção de uma interpretação paisagística global deve ser lembrada,

Geografia Ensino \& Pesquisa, v. 15, n.2, p. 165 176, maio./ago. 2011

Abordagem metodológica do trabalho de campo como prática pedagógica em Geografia com esforços para o entendimento de sua evolução e dinâmica, indo ao encontro da contextualização da fisiologia da paisagem.

Não se pode perder de vista o papel do campo como fonte de conhecimento, e suas conseqüências para o ensino como o local a ser enfatizado no fazer Geografia, enquanto prática. 
O campo representa tanto 0 local de onde se extraem as informações para as elaborações teóricas, como o local onde tais teorias são testadas.

Ao observar uma paisagem é preciso selecionar aquilo que se quer interpretar, pois a noção da observação "completa" evidentemente não tem sentido algum, uma vez que observar é sempre selecionar, estruturar e, portanto, abandonar o que não se utiliza.

A observação científica é ao mesmo tempo ativa e seletiva, sendo procedida e guiada por hipóteses e/ou teorias que nos indicam quais os fatos ou fenômenos são mais relevantes para os nossos interesses. Mas, ao mesmo tempo em que se observa automaticamente se interpreta, através de um esforço mental, na tentativa de apreender o objeto observado.

Duas ou mais pessoas observando um mesmo objeto ou a mesma paisagem podem fazer diferentes interpretações. 0 mesmo objeto ou fenômeno pode ser visto e apreendido de maneiras diferentes por diferentes pessoas, em função de suas diferentes formações profissionais.

Weatheral (1970) assegura que os acontecimentos que podem ser observados, diretamente, através dos sentidos, correspondem a uma diminuta fração da gama de fenômenos físicos de que se conhece.

O geógrafo da atualidade necessita superar essa questão, desenvolvendo a capacidade de observar as paisagens de modo integrado, ou seja, procurando relacionar os aspectos do quadro natural com os aspectos sociais e não separadamente, limitando a capacidade de observação.

Atualmente estão disponíveis uma ampla e variada gama de documentação cartográfica e instrumentos que auxiliam na observação e na coleta de dados. Para utilizá-los, o pesquisador deve ter um mínimo de conhecimento sobre os princípios físicos relativos a esses instrumentos, havendo também a necessidade de treinamento.

$\mathrm{Na}$ escolha de determinado aparelho para a observação ou registro de dados, é preciso levar em conta o grau de precisão; quais os recursos disponíveis; verificar se o mesmo atende às necessidades do pesquisador e conhecimentos técnicos para operá-los.

No caso do trabalho de campo em Geografia, quando da necessidade da utilização de documentos e instrumentos de observação, registro, coleta de dados e de medição, é aconselhável que o geógrafo possa dispor de um técnico especializado, para assessorá-lo nesta tarefa.

Ao discorrer sobre a observação científica, Fourez (1995) afirma que quando se observa alguma coisa, é preciso sempre que seja descrita. Portanto, sempre que observar algo (um fato, um fenômeno ou uma paisagem) há a necessidade da descrição, para que fique registrada a observação.

Não se descreve um objeto ou paisagem sem utilizar uma linguagem, que é a maneira cultural de expressar ou estruturar uma determinada visão, uma compreensão a respeito de algo a ser observado. A não utilização de uma linguagem para descrever os fenômenos observados não tem a menor importância para o conhecimento científico.

De certa forma, muitos autores consideram a linguagem uma espécie de construção social, relativa à sua cultura e seus projetos. Nota-se que não se pode observar sem utilizar a linguagem, seja ela verbal ou mental, pois o idioma é uma forma cultural de estruturar uma visão, uma compreensão.

No caso da observação científica a linguagem utilizada é a linguagem técnica, com uma terminologia precisa, bem definida e conceituada. A linguagem técnica permite a compreensão pelos especialistas que militam na mesma área do conhecimento sendo necessária a familiarização com a linguagem técnica.

Geografia Ensino \& Pesquisa, v. 15, n.2, p. 165176, maio./ago. 2011

Cavalcanti, A. P. B. 
No que diz respeito à Geografia Humana, essa discrepância terminológica difere muito mais. Pode-se citar a linguagem específica, advinda da filosofia marxista, utilizada pelos geógrafos críticos, ao descreverem ou explicarem os problemas sociais, que difere também da linguagem matemático/estatística utilizada pelos geógrafos neopositivistas (quantitativos).

Nos departamentos de Geografia, principalmente na área da Geografia Física, é comum se encontrar laboratórios de pesquisa, onde os geógrafos desenvolvem experimentos para as suas pesquisas ou o utilizam para fins didáticos e pedagógicos, como é o caso dos laboratórios de Cartografia, Geomorfologia, Pedologia, Hidrografia.

Para o bom êxito da observação são também necessárias algumas condições para os quais o pesquisador deve estar atento. Uma das principais é ter boas condições físicas, ou seja, órgãos que possam ter sensações normais e corretas, evitando enganos ou distorções no processo de observação, além da utilização de instrumentos para satisfazer o rigor científico e a objetividade, realçando, evidenciando ou tornando acessível, fatos ou fenômenos de interesse, que de outro modo poderiam passar despercebidos pelo observador.

As condições intelectuais do observador também devem ser levadas em conta, para o bom desempenho do processo de observação. Faz-se necessário um bom embasamento teórico conceitual, pleno domínio de sua área de atuação, curiosidade e sagacidade para poder discernir e interpretar os fatos significativos.

Juntamente com as condições intelectuais vêm às condições morais tais como: ter paciência, para resistir à precipitação natural que leva a concluir resultados antes do tempo necessário; coragem, para enfrentar os perigos e simplicidade, ou seja, liberdade e isenção de toda preocupação com o resultado final das observações, respeitando o resultado a que se chegou, seja ou não de agrado do pesquisador.

\section{Coleta de dados no trabalho de campo em Geografia}

Os instrumentos de coleta de dados no trabalho de campo em Geografia, de modo geral, oferecem esboços práticos que servem de orientação na montagem dos formulários, roteiros de entrevistas, questionários, opiniões e atitudes, além de indicações sobre o tempo e o material necessário à realização da referida pesquisa.

A maneira mais eficiente para a execução de uma pesquisa através da coleta de dados em campo é elaborar um bom planejamento da mesma. Na execução da aula de campo deve-se, de antemão, definir ainda na fase do projeto, onde será realizada a referida aula, identificando pontos principais para o levantamento dos dados; que abrangência de pessoas será entrevistada, ou se serão todos os envolvidos na questão; se inclui levantamento de documentos e finalmente por amostragem do total.

Outro aspecto importante é o perfeito entrosamento das tarefas organizacionais e administrativas com as tarefas científicas, obedecendo aos prazos estipulados, os orçamentos previstos e o preparo pessoal. Quanto mais planejamento for realizado previamente, menos desperdício de tempo haverá no trabalho de campo propriamente dito, facilitando a etapa seguinte.

A partir do início das tarefas de investigação é necessário preparar não só os instrumentos

Abordagem metodológica do trabalho de campo como prática pedagógica em Geografia e fichários. Com relação aos fichários, normalmente utilizam-se três tipos: os fichários de 
documentação, em que aparecem os documentos já lidos ou a serem consultados, com as devidas referências; os fichários de pessoas, que serão visitadas ou entrevistadas ou que se pretenda visitar, com alguns dados essenciais; e os fichários dos indivíduos pesquisados, vistos no sentido estatístico: pessoas, famílias, classes sociais, comércios, indústrias, transportes, salários, etc.

Esta documentação deve contar, também, resumos de obras sobre o tema e/ou a área da pesquisa, recortes de periódicos, notas e outros materiais necessários à ampliação de conhecimentos, cuidadosamente organizados.

Neste trabalho devem-se aplicar os instrumentos elaborados e selecionados, a fim de se efetuar a coleta de dados previstos, exigindo do pesquisador um esforço pessoal, bem como um cuidadoso registro dos dados, perseverança e paciência.

Segundo Viadana (2005) o campo é o laboratório do geógrafo, implicando em considerar dois importantes comportamentos para esta prática: o primeiro de caráter pedagógico como técnica de ensino da ciência geográfica e o segundo é exigido quando do levantamento de dados informativos, um estudo sistematizado, considerando aspectos fisiográficos, biológicos e sociais.

Para os procedimentos da leitura da paisagem, devem-se realizar observações e anotações no diário (caderneta) de campo, procedendo-se a observação participante, com o acompanhamento junto às atividades programadas, registro imediato dos acontecimentos e sua conseqüente anotação no diário.

Geralmente cometem-se alguns erros quando da coleta de dados, devendo-se evitar mudanças radicais no plano de pesquisa devido a conveniências administrativas e a escolha de medidas pouco adequadas e sem o conhecimento suficiente que garanta a sua correta aplicação, produzindo erros de medição.

É necessário ainda ficar atento para as possiveis falhas no relacionamento com os sujeitos da pesquisa, bem como a falta de avaliação das medidas disponíveis, antes de decidir aquelas que serão utilizadas na pesquisa.

Outro aspecto importante que deve ser levado em conta quando da coleta de dados, referese a maneira de conseguir as informações necessárias para a pesquisa, a saber: (i) estabelecer previamente de comum acordo com o pesquisado (os) o local e a hora das entrevistas, deixando (os) à vontade, pois os mesmos não estão disponíveis a qualquer tempo; (ii) ter sempre em mente que não é obrigação do pesquisado responder as perguntas do pesquisador; (iii) solicitar autorização prévia para anotar ou gravar as informações obtidas; (iv) refazer a pergunta com outras palavras, se for necessário, tendo o cuidado de não induzir a resposta.

Para a execução da pesquisa propriamente dita, através da coleta de dados, faz-se necessário a especificação do universo ou da amostra a ser abrangida na pesquisa de campo. 0 procedimento mais utilizado para a averiguação de sua validade é através de testes preliminares, consistindo em verificar se os instrumentos (técnicas) da pesquisa têm realmente condições de garantir os resultados isentos de erros.

Independentemente da(s) técnica(s) escolhida(s), deve-se descrever as formas de sua aplicação, indicando como será processada a tabulação dos dados obtidos. Um controle rigoroso na aplicação desta(s) técnica(s) é fundamental para evitarem equívocos e falhas resultantes de mau encaminhamento durante a coleta de dados, seja através de pesquisadores inexperientes ou de informantes tendenciosos.

De modo geral, este pré-teste é aplicado em uma pequena parte da população, do universo Geografia Ensino \& Pesquisa, v. 15, n.2, p. 165 176, maio./ago. 2011

Cavalcanti, A. P. B. ou da amostra, antes de ser aplicado definitivamente, com a finalidade de que a pesquisa 
chegue a um resultado confiável, devendo-se proceder à especificação da área de execução (espaço físico); da população a ser atingida pela pesquisa; da explicitação da forma de seleção dos sujeitos pesquisados e do tipo de amostra e determinação de seu tamanho.

$\mathrm{Na}$ ciência geográfica os instrumentos de coleta de dados mais freqüentes: a entrevista e 0 questionário. Pelo fato de possuírem uma lista de indagações que ao serem respondidas, oferecem ao pesquisador as informações necessárias para o pleno êxito de sua pesquisa, obtendo-se um conhecimento verbal do fato ou fenômeno pelo pesquisado, apesar de que em alguns casos, o pesquisador não terá a oportunidade de observar diretamente os acontecimentos.

Estes instrumentos devem ser aplicados por pesquisadores experientes, capazes de determinar a validade dos métodos e dos procedimentos utilizados, não sendo possível, nem sempre, prever todas as dificuldades e problemas decorrentes de uma pesquisa que envolva coleta de dados.

Os métodos e procedimentos podem não funcionar em função das perguntas mal formuladas, de linguagem inacessível ou subjetiva. Os pesquisados podem reagir ou se mostrarem duvidosos e a amostra inviável (extensa ou demorada).

Para que a pesquisa ofereça boas condições científicas, certas exigências devem ser levadas em consideração, tais como: precisão, consistência e objetividade dos instrumentos (técnicas) escolhidos; criteriosa seleção da amostra; validade dos dados recolhidos, necessários à pesquisa; fidedignidade dos dados coletados (obtenção dos mesmos resultados).

Através da pesquisa de campo, onde serão coletados dados de acordo com os procedimentos indicados anteriormente, deve-se elaborá-los e classificá-los de forma sistemática, através de uma seqüência lógica de etapas, abrangendo a seleção, codificação e tabulação.

A seleção é o exame detalhado dos dados coletados, devendo-se processar uma verificação crítica, com o intuito de identificação das falhas, evitando-se informações incompletas ou distorcidas, que poderão prejudicar o resultado da pesquisa. Em alguns casos o pesquisador por não observar os aspectos mais importantes, registra uma enorme quantidade de dados; em outros casos, os registros ficam sem um detalhamento suficiente.

O cuidadoso trabalho de seleção de dados, pode reconhecer o excesso e a falta de informações, neste caso, o retorno ao campo, com o objetivo de reaplicação do(s) instrumento (s) de observação, poderá sanar tais falhas.

A codificação é a técnica operacional utilizada onde os dados são transformados em símbolos, podendo ser tabelados ou contados, dividindo-se em duas partes: (i) classificação dos dados, agrupando-os em categorias; (ii) atribuição de um código, número ou letra, tendo cada um deles um significado. Na codificação ocorre a transformação do qualitativo para 0 quantitativo, facilitando não só a tabulação dos dados, como também sua comunicação.

A tabulação é a disposição dos dados em tabelas, possibilitando maior facilidade na verificação das interpretações entre eles, sendo classificados pela divisão em grupos e reunidos de modo que haja comprovação ou não das idéias expostas. Isto permite sintetizar os dados conseguidos pelas diferentes categorias e representá-los graficamente, podendo ser compreendidos e interpretados com mais facilidade e eficiência. Geralmente emprega-se 0 computador, pois diminui as margens de erro e agiliza o tempo, com menos esforço. 


\section{Trabalho de campo (aula expositiva prática e aferição da verdade terrestre)}

O trabalho de campo é a forma clássica e tradicional dos geógrafos levantarem dados e informações. Desde o surgimento da denominada Geografia Moderna, com Humboldt e Ritter, na Alemanha no século XIX, esta prática vem sendo valorizada e empregada até os dias atuais.

Humboldt, considerado um dos maiores naturalistas do mundo, foi um grande observador da natureza. Utilizava um método que denominou de empirismo raciocinado, valorizando a intuição, a partir da observação das paisagens, desenvolvendo uma Geografia naturalista, inteiramente baseada no trabalho de campo.

Apesar de ser considerado um geógrafo de gabinete, Ritter foi também um importante observador da natureza, estudando e observando a individualidade dos lugares, em relação aos povos que ali habitavam, tendo uma concepção organicista-finalista da natureza e desenvolveu a Geografia Regional, com ênfase no elemento humano e suas relações com o meio ambiente.

Os geógrafos sempre procuraram observar as paisagens e a sua organização espacial, através da prática de campo. A esse respeito Muller Filho (1988) acrescenta que a fonte ideal para a obtenção de informações é a própria paisagem, por que ela é a realidade à disposição da capacidade de interpretação do investigador.

Denomina-se então campo, o local, a área, a região, aonde o pesquisador vai para observar, registrar, descrever e explicar os fatos ou fenômenos geográficos.

Ao explicitar o significado da palavra campo, Silva (1982) salienta que em um sentido empírico tradicional o campo confunde-se com o lugar que se percebe e do qual se pode ter vivência cotidiana sendo parte de uma área e de uma região.

Através da pesquisa de campo o geógrafo entra em contato com a realidade, procurando compreender a sua complexidade, ou seja, o produto da interação entre os elementos do quadro natural modificado e transformado pela dinâmica social, exigindo do pesquisador toda uma fundamentação teórica - conceitual para aprender a totalidade observada.

Por outro lado, todos os que militam no campo da Geografia, sejam professores/pesquisadores ou acadêmicos, estão acostumados com uma terminologia muito utilizada e difundida: trabalho de campo; pesquisa de campo; excursão geográfica; excursão didática; ida ao campo; estudo do meio, etc. Apesar dos termos serem utilizados como sinônimos e parecer indicar a mesma coisa, isto não é verdade. É preciso diferenciar e especificar o que significam essas expressões, evitando maiores confusões ou mal entendidos.

Há uma diferença fundamental entre uma pesquisa de campo, cujo objetivo é o desenvolvimento de uma pesquisa por parte do pesquisador (Monografia de graduação, Dissertação de mestrado e Tese de doutorado), de um trabalho de campo, cuja finalidade é uma excursão com acadêmicos, com fins puramente didáticos e pedagógicos, ou mesmo uma saída ao campo, com fins turísticos ou de recreação.

Radaelli da Silva (2002) acrescenta que como instrumento, técnica, método ou meio, a pesquisa de campo vem a ser toda atividade que proporciona a construção do conhecimento em ambiente externo ao das quatro paredes, através da concretização de experiências que promovam a observação, a percepção, o contato, o registro, a descrição e representação, a análise e reflexão crítica de uma dada realidade, bem como a elaboração conceitual como parte de um processo intelectual mais amplo, que é o ensino.

Considerado como um instrumento didático-pedagógico, um processo, uma técnica, ou mesmo um método, a pesquisa de campo é de importância fundamental para a Geografia, pois é

Geografia Ensino \& Pesquisa, v. 15, n.2, p. 165 176, maio./ago. 2011

Cavalcanti, A. P. B. 
através dele, que os geógrafos entram em contato com a realidade, construindo o conhecimento geográfico.

O trabalho de campo é concebido como um importante instrumento na formação de professores/pesquisadores, pois se constitui em um meio para desenvolver uma percepção apreciativa sobre o território, num contexto menos formal que o da sala de aula, e para construir alternativas de trabalho que sejam relevantes para a prática pedagógica em Geografia.

Alguns autores o consideram como um verdadeiro método para o desenvolvimento do conhecimento geográfico, bem como para a prática de ensino.

Não se pode perder de vista o papel do campo como fonte de conhecimento, e suas conseqüências para o ensino como o local a ser enfatizado no fazer Geografia, enquanto prática. 0 campo representa tanto o local de onde se extraem as informações para as elaborações teóricas, como o local onde tais teorias são testadas.

O trabalho de campo é, ao mesmo tempo, fonte de informações e crítica da produção científica geográfica, peça fundamental para a assimilação e construção de seus conceitos (Compiani, 1991).

Sendo bastante valorizada como recurso didático, propicia aos acadêmicos, um contato direto com a realidade observada, obtendo-se uma nova dimensão dos temas tratados em sala de aula, servindo entre tantas finalidades, estimular o estudo articulado com as diferentes disciplinas.

\section{Conclusões}

Deve-se enfatizar a importância do trabalho de campo como recurso didático, porque oferece potencialidades formativas que devem ser levadas em consideração no processo ensino-aprendizagem como uma das técnicas pedagógicas mais acessíveis e eficazes ao pesquisador da ciência geográfica.

O trabalho de campo, enfim, como um método eficiente na produção da ciência geográfica e na prática de ensino, pode proporcionar aos acadêmicos a oportunidade de confronto com a realidade com as discussões teóricas realizadas em sala de aula, possibilitando a atuação conjunta dos professores/pesquisadores das disciplinas envolvidas e a percepção das interfaces existente entre elas.

Ressalte-se, mais uma vez, a importância que tem o trabalho de campo para a Geografia, pois desde os tempos mais remotos, até os dias atuais, esse resulta o procedimento clássico e tradicional do geógrafo; levantar dados e informações, bem como desenvolver o processo pedagógico do ensino e prática da ciência geográfica.

\section{Referencias}

CAVALCANTI, A. P. B. Métodos e Técnicas da Análise Ambiental (Guia para estudos do meio ambiente).

Geografia Ensino \& Pesquisa, v. 15, n.2, p. 165 176, maio./ago. 2011

Abordagem metodológica do trabalho de campo como prática pedagógica em Geografia
Teresina: UFPI/CCHL/ DGH, 2006.

COMPIANI, M. A relevância das atividades de campo no ensino de Geologia na formação de professores de Ciências. Caderno IG, UNICAMP, Campinas: v. 1, n.2, p.2-25, 1991. 
DAVID, C. Trabalho de campo: limites e contribuições para a pesquisa geográfica, GEO-UERJ. Revista do Departamento de Geografia. Universidade do Estado do Rio de Janeiro, Rio de Janeiro: $n^{0}$ 11, p.19-24, 2002.

FOUREZ, G. A Construção das Ciências (Introdução à Filosofia e a Ética da Ciência), São Paulo: Ed. da UNESP, 1995.

GIL, A. C. Método e Técnicas de Pesquisa Social. São Paulo: Ed. Atlas S.A., 1995.

KAPLAN, A. A Conduta na pesquisa. (Metodologia para as ciências do comportamento) São Paulo: Ed. Herder e EDUSP, 1969.

MÜLLER FILHO, I. L. - Consideração para uma compreensão da abordagem clássica em Geografia. Geografia, Rio Claro: v. 13, n. 215, p. 1-19, 1988.

OLIVEIRA, S. L. Tratado de Metodologia Científica. Projetos de Pesquisas, IGI, ICC, Monografias, Dissertações e Teses, São Paulo: Ed. Pioneira, 1988.

RADAELLI DA SILVA, A. M. Trabalho de Campo: prática "andante" de fazer Geografia. Revista do Departamento de Geografia, Rio de Janeiro: $n^{0}$ 11, p. 61-74, 2002.

SILVA, A. C. Natureza do trabalho de campo em Geografia Humana e suas limitações. Revista do Departamento de Geografia, São Paulo: Universidade de São Paulo, nº 1, p. 99-104, 1982.

VIADANA, A. G. A excursão geográfica didática (Pontal do Triângulo Mineiro). Rio Claro/SP, LPM - IGCE / UNESP, 2005.

WEATHERAL, M. Método Científico, São Paulo: EDUSP e Ed. Polígono, 1970.

\section{Correspondência}

Agostinho Agostinho Paula Brito Cavalcanti -

E- mail: agos@ufpi.br

Recebido em 30 de março de 2011.

Revisado pelo autor em 23 de junho de 2011.

Aprovado em 28 de agosto de 2011.

Geografia Ensino \& Pesquisa, v. 15, n.2, p. 165 